\title{
İstilacı Böcek Türlerinin Mücadelesinin Yönetimi: Anoplophora chinensis (Forster, 1771) (Coleoptera: Cerambycidae) Örneği
}

\author{
Vildan Bozkurt ${ }^{1}{ }^{*}$ \\ 'Zirai Mücadele Merkez Araştırma Enstitüsü Müdürlügü, 06172, Yenimahalle, Ankara.

\section{Özet}

Uluslararası ticaret birçok böcek türünün bir yerden başka bir ülkeye taşınmasında önemli rol oynamaktadir. Itthal edilen süs bitkileri yoluyla taşınabilen zararlılardan birisi de turunçgil uzun antenli böceği Anoplophora chinensis (Forster, 1771) (Coleoptera: Cerambycidae) olup, Bitki Karantinası Yönetmeliği'nin Ek-1 B-Türkiye'de sinırlı olarak bulunan ve ithale mani teșkil eden karantinaya tabi zararlı organizmalar listesinde yer almaktadır. Bu tür, bitkinin odun dokusu içerisinde yumurta, larva, pupa dönemlerinde tașınabilmektedir. Dișiler genellikle ağacın gövdesinin topraktan $60 \mathrm{~cm}$ yükseklikteki yüzeyine ya da dıșarıda kalmıș kök bölümlerindeki kabuklar üzerinde mandibulası ile T biçiminde yarıklar açarak bu yarıkların her birine bir adet yumurta bırakmaktadır. Zararlının erginleri doğada mayıs ve ekim ayları arasındaki dönemde bulunmaktadır. Yumurta, larva ve pupa dönemleri ağacın gövdesi içerisinde bulunduğundan varlı̆̆ının dışarıdan tespit edilmesi oldukça zordur. Ancak, ağacın gövdesinden çıkış yapan erginlerin oluşturduğu 1-1,5 cm çapındaki çıkış deliklerinin ya da erginlerin görülmesi ile zararlının varlı̆̆ tespit edilebilmektedir. Sürgünlerde beslenme belirtilerinin ve gövdede talaş artıklarının görülmesi de zararlının varlığına ișaret olabilmektedir. Zarar belirtilerinin çoğu ă̆acın yerden 1,5 m yüksekliği civarında görülmektedir. Ergin çıkış delikleri görüldüğünde ise mücadele için geç kalınmıs olmaktadır. Bu çalıșmada turunçgil uzun antenli böceği A. chinensis'in kısa biyolojisi, konukçuları, zarar șekli, mücadelesi ve eradikasyonu konusunda Türkiye'de ve dünyada yürütülen çalışmalar ile alınması gereken karantina önlemleri hakkında bilgi verilmesi amaçlanmıștır.

\section{Management of Invasive Insect Species: An Example of Anoplophora chinensis (Forster, 1771) (Coleoptera: Cerambycidae)}

\begin{abstract}
International trade plays an important role in the transport of many insect species from one place to another. Anoplophora chinensis (Forster, 1771) (Coleoptera: Cerambycidae) is one of the harmful insects that can be transported through the imported ornamental plants. It is listed on Annex-1B the harmful organisms that have limited existence in Turkey, that are subject to quarantine and that hinder importation of the plant quarantine regulation in Turkey. This species can be transported in egg, larva, pupa periods within the xylem of the plant. Females cut a T-shaped slit on the bole of the trees about $60 \mathrm{~cm}$ high from the ground or on the exposed roots with their mandibles and deposit one egg in each of these slits. Adults of the insects are seen in the period between May and October. Since eggs, larvae and pupae are located inside the tree's thrunk, it is very difficult to detect its presence from the outside. However, it is possible to determine the presence of a 1-1.5 cm diameter exit hole or see adults that exit from the tree's trunk. The presence of feeding signs in the shoots and sawdust debris on the trunk can also indicate the presence of damage. Most of the damage symptoms are seen around the height of $1.5 \mathrm{~m}$ from the ground. When the adult exit holes are seen, it is too late for the control. In this study it is aimed to give information about citrus longhorn beetle A. chinensis short biology, hosts, damage, control and eradication measures carried out in Turkey and in the world and quarantine measures need to be taken.
\end{abstract}

Keywords

Anoplophora chinensis, Cerambycidae, Coleoptera, Control, Eradication

\section{Giriş}

Ülkemize yurtdışından her yıl çok sayıda bitki ve bitkisel üretim materyali ithal edilmektedir. Uluslararası ticaret birçok böcek türünün bir yerden başka bir ülkeye taşınmasında önemli rol oynamaktadır. Türkiye'de özellikle dış mekan süs bitkileri ihtiyacı belediyelerin ithal ettiği ağaçlardan karșılanmaktadır. En fazla ithal edilen canlı bitkiler arasında saksılı iç mekan süs bitkileri, ağaçlar, fide ve fidanlar bulunmaktadır. İthal edilen süs bitkileri şehirlerdeki peyzaj çalışmalarında kullanılmaktadır. İthal edilen süs bitkilerinin dikildiği yerlerde istilacı böcek türleri ortaya çıkabilmektedir. Bu türlerden birisi olan Turunçgil Uzun Antenli Böceği olarak bilinen Anoplophora chinensis'in ülkemizde varlığı belirlenmiş̧ir. 
A. chinensis'in Ülkemizde varlığı ilk defa 12 Haziran 2014 tarihinde Şile-İstanbul Kumbaba Fidanlığı'nda Acer palmatum, A. saccharum ve Salix caprea üzerinde tespit edilmiştir. Daha sonra İstanbul'da 2014 yılında Temmuz ayı içerisinde yapılan arazi kontrolleri sırasında Abdi İpekçi Arena stadı çevresindeki akçaağaçların kök bölgesinde ergin böcekler yakalanmış olup, 13.02.2015 tarihinde ise Zeytinburnu çevresinde ve Yenikapı sahilinde tespitler yapılmıştır (Hizal vd. 2015).

Bitki Karantinası Yönetmeliğinin Ek 1-B listesinde bulunmakta olan bu zararlı türün Türkiye’ye ithal edilen süs bitkisi türleri ile girmiş olabileceği düşünülmektedir. Zararlı organizmanın muhtemel yayılma yolları olarak dikim amaçlı olarak ithal edilen bulaşık bitkilerle kolaylıkla temiz alanlara giriş yapabilmesi mümkün olacağından ülkemize giriş yapmış olan zararlı organizmanın yayılma olasılığı yüksek olarak değerlendirilmektedir. Özellikle Akçaağaç (Acer spp.) türlerinin ithali en önemli taşınma yolu olarak görülmektedir. Çap1 $1 \mathrm{~cm}$ civarında olan Akçaağaç bitkilerinde bile zararlının larvası tespit edilmiştir. Ayrıca, Asya ülkelerinden ithal edilen bonsai türü bitkilerle de giriş yapabilmektedir. Ağaç içerisinde yumurta, larva ve pupa döneminde dikim amaçlı olarak bitki ithal edilmesi ile taşınabilmektedir. Bitkiler üzerinde zararlının tespit edilmesi oldukça zordur. Ancak ergin çıkışı olduktan sonra ağaç üzerindeki $1 \mathrm{~cm}$ civarındaki ergin çıkış delikleri görülebilmektedir. Zararlının yüksek popülasyon yoğunluğunda $2 \mathrm{~km}$ ’den fazla uçabildiği ve hızla yayılabildiği bildirilmektedir (Adachi 1990). Ancak uzun mesafelere bulaşık bitkilerin taşınması ile de yayılabilmektedir. Yüksek popülasyon oluşturarak yeni bir alanda çıkış yapması birkaç yıl alabilmektedir. Avrupa'da zararlının bulunduğu İtalya gibi ülkeler ile Ülkemizdeki iklim şartları zararlının yaşaması için uygundur. Zararlı soğuk iklim koşullarına sahip yerlerde de yaşamını sürdürebilmektedir (Baker ve Eyre 2006). Zararlının dünyadaki yayılışı en yoğun Çin, Japonya, Kore, Malezya, Myanmar, Tayvan, Vietnam, Endonezya ve Filipinlerde görülmektedir. İstilacı yabancı tür olarak Kuzey Amerika, Almanya, Danimarka, Hollanda, Hırvatistan, Finlandiya, Fransa, İngiltere, İsviçre, İtalya, Litvanya, Polonya ve Romanya'da bulunmaktadır (EPPO 2015).

\section{Materyal ve Yöntem}

İstanbul'da 2014 yılında Hizal vd. (2015) tarafindan yapılan tespitlerden sonra Anoplophora chinensis ile ilgili yeni örnekler alınarak teşhis çalışması tekrar yapılmıştır. 2015 yılında İstanbul İl Gıda Tarım ve Hayvancılık Müdürlüğü tarafından teşhis edilmek üzere Zirai Mücadele Merkez Araştırma Enstitüsü’ne gönderilen böcek numunesi, Gazi Üniversitesi Biyoloji bölümünden Prof. Dr. Hüseyin Özdikmen tarafından teşhis edilmiş olup, söz konusu zararlı organizmanın Anoplophora chinensis (Forster) (Coleoptera: Cerambycidae) olduğu belirlenmiştir. Teşhis edilen böcek örnekleri Zirai Mücadele Merkez Araştırma Enstitüsü Müdürlüğü’nde Tarımsal Fauna ve Mikroflora Bölümü Nazife Tuatay Bitki Koruma Müzesinde muhafaza edilmektedir.

\subsection{Tanımı ve Biyolojisi}

Ergin bireyin vücudu siyah renkli ve elytra üzeri beyaz noktalıdır. Anten siyah renkli, segmentlerin taban kısmı grimsi mavidir. Dişide anten vücudun yaklaşık 1,2'si kadar uzunlukta, erkekte ise vücudun 2 katı kadar uzunluktadır. Erginler mayıs ve ağustos ayları arasında yaşamaktadır (Şekil 1).
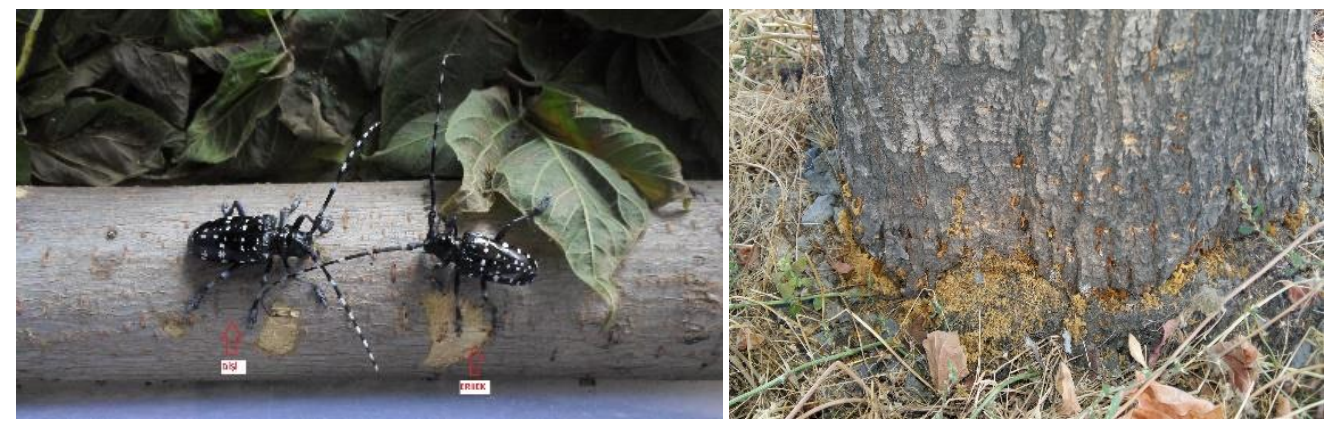

Şekil 1: Anoplophora chinensis (Forster 1771) ergini ve yumurta bırakma yerleri (Altunışık 2015)

Dişiler genellikle ağacın gövdesinin topraktan $60 \mathrm{~cm}$ yüksekteki yüzeyine ya da dışarıda kalmış kök bölümlerindeki kabuklara mandibulası ile T biçiminde yarıklar açarak her birine bir yumurta bırakmaktadır. Yumurtalardan çıkan larvalar öncelikle kambiyum tabakası ile beslenir ve zaman içinde ağaçların odun dokusu içine girerek gelişimlerini tamamlarlar (Şekil 2). 

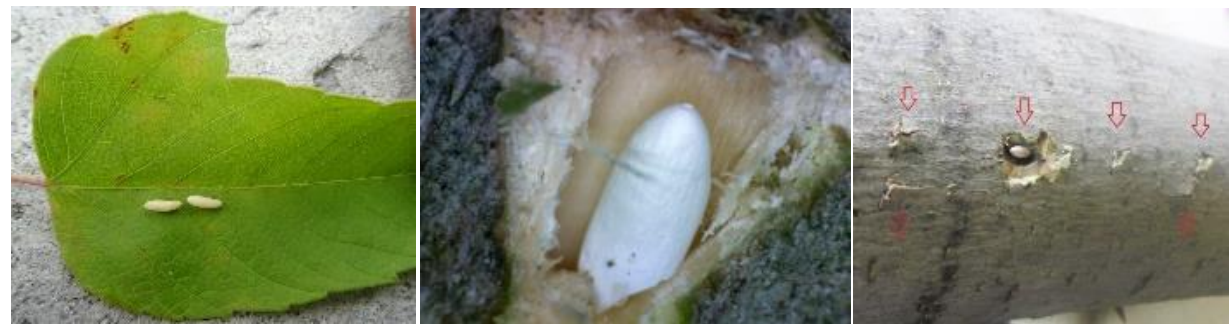

Şekil 2: Anoplophora chinensis (Forster 1771) yumurtası (Altunışık 2015)

Larvalar ağaçların odun dokusunda beslenerek kalitesinin bozulmasına neden olmaktadır. Kışı larva nadiren de pupa döneminde geçirmektedir. Odun dokusunda larva döneminde beslendiği alanda pupa olmaktadır (Şekil 3).
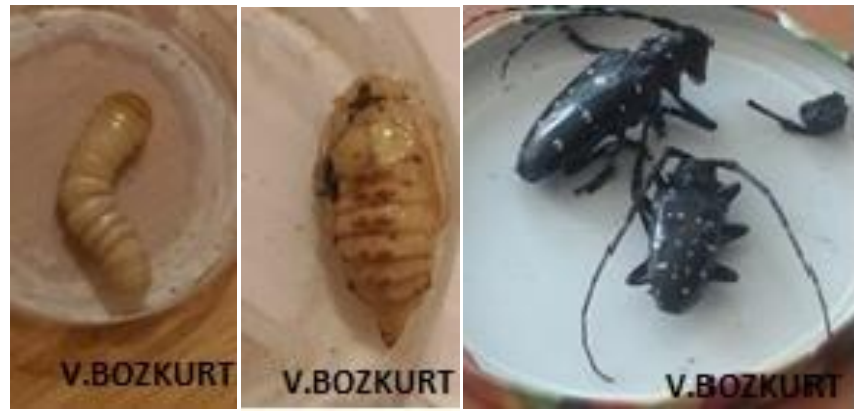

Şekil 3: Anoplophora chinensis (Forster 1771)'in larva, pupa ve erginleri

Ergin olduktan sonra ağacın dallarından çıkış yaptığı 1-1,5 cm çapındaki delikler dışarıdan görülmektedir (Şekil 4). Yeterli besin kaynakları bulunduğu sürece fazla hareket etmezler. Bulundukları ağacın civarında $50 \mathrm{~m}$ kadar hareket ederler. Dişilerin bıraktığı yumurta sayısı zararlının beslenme durumuna ve yaşadığı bölgeye göre 70 ile 194 adet arasında değişebilmektedir. Yılda tek döl verir. Ancak, iklime ve beslenme koşullarına bağlı olarak gelişimini tamamlaması 1-2 y1l sürmektedir (EFSA 2010; Van der Gaag vd. 2010).

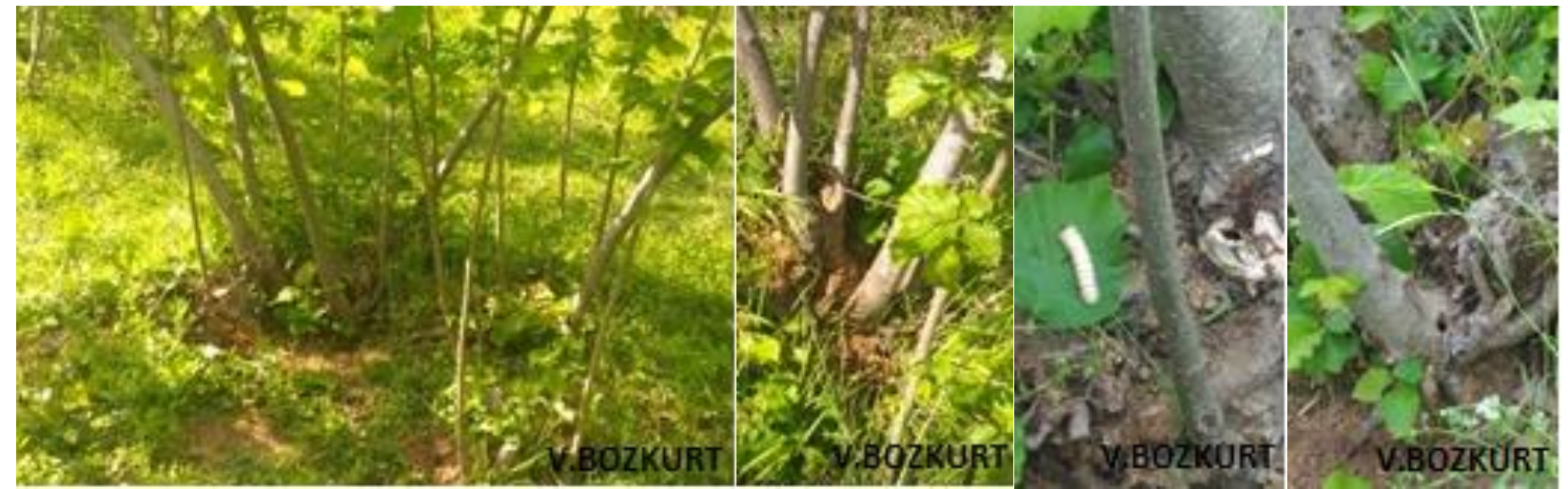

Şekil 4: Anoplophora chinensis (Forster 1771)'in zararı, larvası ve ergin çıkış deliği

\subsection{Konukçuları}

A. chinensis polifag bir tür olduğundan çok geniş bir konukçu dizisine sahiptir. Zararlının konukçuları arasında yapraklı park ve süs ağaçları, turunçgil ve fındık ağaçları bulunmaktadır. Yaklaşık 19 familyayı kapsayan 68 türde zarar yaptığı tespit edilmiştir. Zararlının mevcut bulunduğu doğal yayılış alanlarında özellikle Citrus cinsine bağlı bitki türlerinde (turunç, limon, mandalina gibi) önemli zararlara sebep olduğu bildirilmektedir. Zarar yaptığı bitki türleri Acer spp., (akçaağaç), Aesculus hippocastanum,(at kestanesi), Alnus spp. (kızılağaç), Betula spp. (huş ağacı), Cornus spp., (kızılcık), Corylus spp., (findık), Cotoneaster spp., (dağ muşmulası), Crataegus spp., (alıç), Fagus spp.,(kayın), Ficus spp., Hibiscus spp., Lagerstroemia spp., Mallotus spp., Malus spp., (elma), Morus spp.(dut), Platanus spp., (çınar), Populus spp., (kavak), Prunus spp., (kiraz), Pyrus spp., (armut), Salix spp., (söğüt), Rosa spp. (gül), Ulmus spp.(karaağaç) bulunmaktadir (Smith vd. 1997). 


\subsection{Zarar Şekli}

Turunçgil uzun antenli böceği konukçu olduğu bitki türlerine çok ciddi zararlar vererek ölümüne yol açan bir böcektir Asıl zararı larvalar yapmaktadır. Ağacın gövdesine bırakılan yumurtalardan çıkan larvalar öncelikle kambiyum tabakası ile beslenir ve zaman içinde ağaçların odun dokusu içine girerek gelişimlerini tamamlarlar. Larvalar ağaçların odun dokusunda beslenerek galeri açmak suretiyle zararlı olmaktadır. Larvaların saldırısı ile ağaçlar zayıflar ve hastalık ve rüzgar zararına daha hassas hale gelirler ve kısa sürede ağacın ölümüne sebep olurlar. Erginler ince dalları ve kabukları yiyerek zarar verirler (Maspero vd. 2007). Şekil 5'de A. chinensis'in larva zararı ve ergin çıkış delikleri görülmektedir.

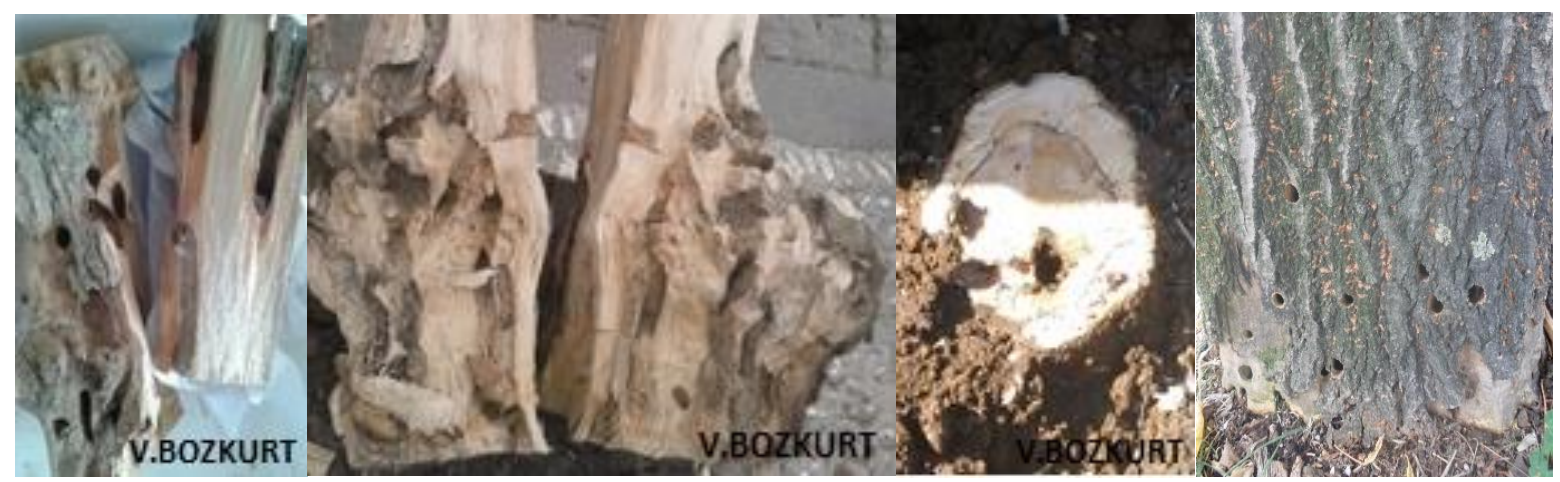

Şekil 5: Anoplophora chinensis (Forster 1771) larva zararı ve ergin çıkıs delikleri

\subsection{Türkiye'de Yürütülen Mücadele ve Eradikasyon Çalışmaları}

İstanbul'da yapılan tespitlerden sonra Ülkemizde varlığı bilinmeyen zararlı statüsünde bulunmakta olan Anoplophora chinensis ile ilgili teşhis çalışması yapılmıştır. 2015 yılında hızlı tarama metodu ile Zararlı Risk Analizi yürütülerek zararlının Türkiye için risk oluşturduğu ortaya konulmuştur. Yapılan zararlı risk değerlendirmesi sonucunda 1/4/2016 tarihinde yürürlüğe girmiş olan Bitki Karantinası Yönetmeği değişikliği ile A. chinensis'in Bitki Karantinas1 Yönetmeliği’nin Ek 1-A listesinden çıkarılarak EK 1-B listesine alınmıştır. Alınacak önlemlerin ortaya konması amacıyla 17 Haziran 2014 te Resmi Gazetede "Ani meşe ölümü ve çam çıralı kanser hastalığ ile turunçgil uzun antenli böceği ve kestane gal arısı mücadelesi hakkında yönetmelik" yayınlanmıştır. Sürvey Talimatı hazırlanarak ülkesel sürvey çalışmaları başlatılmıştır. Zararlının eradikasyonu için eylem planı hazırlanmıştır. Eylem Planı kapsamında İstanbul'da tüm yeşil alanlarda ve fidanlıklarda sürvey çalışmaları yürütülmeye devam edilmektedir. Zararlının eradikasyonu için; İstanbul İl Gıda Tarım ve Hayvancılık Müdürlüğü ve İstanbul Büyükşehir Belediyesi Park ve Bahçeler Müdürlüğü ekipleri tarafından zararlı ile mücadele ve eradikasyon çalışmaları yürütülmektedir. Bölgede bulaşık bulunan bütün ağaçlar işaretlenerek kesilmekte ve yonga haline getirilmekte, yakılarak imha edilmektedir. Eradikasyon çalışması kapsamında akçaağaç, söğüt, kavak, çınar gibi çeşitli ağaç türleri imha edilmektedir. Zararlının erginlerinin aktif olduğu Mayıs-Ekim ayları arasındaki dönemde ergin çıkışı görülen ağaçlar işaretlenmektedir. Zararlının aktif olmadığı KasımMart arasındaki dönemde daha önce işaretlenmiş olan ağaçlar kesilmektedir. Bulaşık bulunan ağaçların kök kısımlarının imhası yapılmıştır. Bu işlemlere ilaveten yönetmeliklere uygun olarak larva ve erginlere karşı kimyasal mücadele çalışmaları başlatılmıştır. Ergin uçuşu tespit edilen alanda yeşil aksamda ilaçlama çalışmaları yapılmıştır. A. chinensis ile kimyasal mücadele çalışmaları kapsamında Abdi İpekci Spor Kompleksi merkez alınıp 2 km çevresindeki tüm akçaağaç, atkestanesi, söğüt, oya ve çınar ağaçlarının ilaçlama işlemleri başlatılmıştır (Altunışık 2015). İlaçlamalarda, Gıda Tarım ve Hayvancılık Bakanlığı tarafından geçici ilaç tavsiyesi olarak önerilen Imidacloprid SC 350 etken maddeli insektisit kullanılmaktadır. Ülkesel sürvey çalışmalarına devam edilmektedir. Toplum bilincinin artırılması amacıyla zararlının tanınması ve zarar şekli hakkında liflet hazırlanmıştır. Zararlının konukçusu olmayan ağaç türlerinin dikilmesi tavsiye edilmiştir.

A. chinensis 2018 yılında Doğu Karadeniz Bölgesinde Trabzon Maçka’da (Esiroğlu Mahallesi) findık bahçelerinde görülmüştür. Alınan ergin böcek numunelerinin ilgili konu uzmanı tarafından teşhis çalışmalarının tamamlanmasından sonra Trabzon'da 17 Nisan 2018 tarihinde İl Gıda Tarım ve Hayvancılık Müdürlüğü tarafindan turunçgil uzun antenli böceği ile mücadele toplantısı düzenlenmiştir. Toplantı sonucunda genel sürvey kapsamında bulunan A. chinensis mücadelesi konusunda acil eylem planı hazırlanarak, zararlının tespit edildiği yerlerde alınacak önlemler belirlenmiştir. Trabzon'da findıkta tespit edilen “Turunçgil Uzun Antenli Böceği Anoplophora chinensis (Coleoptera: Cerambycidae)'in Tanımı, Konukçuları, Zararı ve Eradikasyon Çalışmaları” konusunda konu ile ilgili kişilere seminer verilmiştir. Üreticilerin bilinçlendirilmesi amacıyla zararlı türle ilgili yayım ve tanıtım çalışmaları yapılmaya devam edilmektedir. Zararlıya rastlayan üreticilerin İl/İlçe Gıda Tarım ve Hayvancılık Müdürlüklerine başvuruda bulunmaları tavsiye edilmiştir. 


\subsection{Dünya'da Yürütülen Mücadele ve Eradikasyon Çalışmaları}

Avrupa'da zararının bulunuşu ile ilgili yazılı ilk kayıt İtalya'dan 2001 yılında yapılmıştır. Ancak, zararlının İtalya'daki muhtemel varlığının 1997 yılından beri mevcut olduğu ve eradikasyon çalışmalarının halen devam ettiği belirtilmektedir (EPPO 2015) . İtalya'da eradikasyon amacıyla akçaağaç, betula, söğüt, kavak gibi bulaşık ağaçların imhası yapılmıştır. İlk aşamada bulaşık alanın $500 \mathrm{~m}$. çevresinde çalışmalara başlanmıştır. Kamuouyuna bilgilendirme yapılarak çalışmaların gerekçesi açıklanmış ve ağaçların sahipleri bilgilendirilmiştir. Bütün ağaçlar harita üzerinde işaretlenmiştir. İlk aşamada bulaşık ve şüphe duyulan ağaçlar kesilmiş ve uygun bir alanda toplanmıştır. Gövde ve dallar $50 \mathrm{~cm}$ uzunlukta kesilerek bir araya toplanmıştır. Yeni dikilen ağaçlar zararlının konukçusu olmayan ağaç türlerinden seçilmiştir. Zararlının en çok tercih ettiği Betula ve Acer ağaçları yerine hassas olmayan türlerden Ginkgo biloba ve Liquidambar stryciflua türü bitkiler dikilmiştir. İnceleme çalışmalarına üst üste 4 yıl süreli olarak dikkatli olarak zararlının belirtileri görülmeyinceye kadar devam edilmiştir. İtalya Lombardy bölgesindeki sürveylerde 200.000 ağaç incelenmiștir. Bu ağaçların 1.000 adedi bulaşık bulunmuştur. Bulaşık ağaçlar 1 Ekim- 31 Mart tarihleri arasında kış mevsiminde kesilmiştir. Yaklaşık olarak 18.000 adet ağaç kesilerek imha edilmiş ve yerine zararlının konukçusu olmayan 17.000 adet ağaç dikilmiştir. İtalya'da 2005-2013 yılları arasında eradikasyon için 20 milyon Euro harcanmıştır. İtalya'da Anoplophora chinensis ile ilgili yürütülen çalışmalar aşağıda açıklanmıştır.

- Sürvey çalışmaları sırasında bulaşık bulunan ağacın ya da bölgenin çevresinde 1-2 km lik alanda gözle inceleme yapılmışıtır.

- Bulaşık bulunan ağaçlar yaz başında ve sonunda olmak üzere yılda 2 kere kontrol edilmiştir.

- Zararlının bulunabileceği ağaçların nasıl izleneceği konusunda liflet ve poster ile toplum bilincini artırılması sağlanmıştır.

- Bulaşık ağaçların imhası zorunlu tutulmuştur.

- Yeni dikilen ağaçlardan zararlının konukçusu olan ağaçların dikilmesi yasaklanmışır.

- Karantinaya alınan alanda zararlının konukçusu olabilecek ağaç ve bitkilerin ticareti ve nakliyesi yasaklanmıştır.

- Bütün konukçularının Imidacloprid ve Thiacloprid gibi insektisitlerden birisi ile ilaçlanması zorunlu tutulmuştur.

- Bulaşık olduğu düşünülen ağaçların gövdesinden ve köklerinden çıkabilecek erginleri takip etmek için ağaç gövdelerinin ve köklerinin üzeri ağ şeklinde ince metal kafes teli ile kaplanmıştır.

- Bulaşık alandaki Akçaağaç, Çınar, Huş ağacı, Kayın, Gürgen, Fındık, Elma, Armut gibi ana konukçusu olan bitkiler belirlenerek, eradikasyon çalışmalarına bulaşık bulunan alandaki ağaçların imhası ile başlanmıştır.

- Eradikasyon işlemleri 4 aşamadan oluşmaktadır.

a. Bulaşık ağaçların kesilmesi.

b. Kesilen ağaçların karantina alanında çitle çevrili korunaklı bir alanda muhafaza edilmesi.

c. Bulaşık kütüklerin ve köklerin özel bir makine ile ögütülmesi.

d. Bitki materyalin tamamının yonga haline getirilmesi ve yakılması.

İtalya'da erginlerin çıkışı haziran sonunda tepe noktaya çıkmaktadır. Çıkış delikleri çoğunlukla ağacın kök çevresinde ve gövdenin yerden $20 \mathrm{~cm}$ lik yükseklikteki bölümünde bulunur. Seralarda ortalama ergin ömrü 55 gündür. Yumurtaların çoğu haziran sonu ve ağustos başında bırakılır. Yumurtaların bırakıldığı yerler esas olarak ağaç üzerinde bilezik şeklinde yer almaktadır ve yoğunluk genelde yerden $50 \mathrm{~cm}$ yüksekliğe kadar bırakılan yumurtaların yoğunluğu azalmaktadır. Hayat dönemini 2 yılda tamamlamaktadır. Çok az bir kısmı 1 yılda tamamlamaktadır. Yüksek mali değeri olan ağaçların kesiminden kaçınmak için insektisitle mücadele çalışmaları yapılmışı̧ı. Zararlının yayılmasını engellemek ve hareketini azaltmak için erginleri öldürmek için insektisitlerden Thiacloprid $480 \mathrm{~g} / 1$ (Calypso), Spinosad $480 \mathrm{~g} / \mathrm{l}$ (Laser), Thiamethoxam \%25 (Actara $25 \mathrm{WG)}$ gibi ilaçlarla ağaçların alt kısımları mayıs-ekim arasındaki dönemde ilaçlanmaktadır. Bu uygulamaların larvaya etkileri için galerileri kontrol edilmektedir. Ayrıca, bulaşık ağaçlara insektisit enjeksiyonu uygulanmaktadır.

İtalya'da bulaşık ve bulaşık olmayan konukçu ağaçlar Deltamethrin ile yılda 3 kez ilaçlanmıştır (Van der Gaag 2008). Fransa'da ise bulaşık ağaçlar yazın çıkan erginleri öldürmek için Bifenthrin ile ilaçlanmıştır (Hérard vd. 2005). İngiltere'de orman ağaçları için ruhsatlı olan cypermethrin, deltamethrin, bifenthrin, diflubenzuron ve chlorpyrifos gibi kontak etkili ilaçlar kullanılmıştır (https://secure.fera.defra.gov.uk/liaison/secure/). Avusturya'da ithal edilen bitkiler içinde, köpekle, bulaşık bitki aranmaktadır. Avrupa Birliği'nde 2008 yılında yürütülen çalışmalarda A. glabripennis ve A. chinensis mücadele masraflarının 3,3 milyon Euro olduğu bildirilmektedir (Hérard ve Roques 2009).

2002 yılında İtalya'da sürveyler sırasında toplanan örneklerden erken dönem A. chinensis larvalarında sekiz Hymenoptera türü bulunmuştur. Bunlar: Sclerodermus sp. (Bethylidae), Spathius erythrocephalus (Braconidae), Calosota agrili ve Eupelmus aloysii (Eupelmidae), Eurytoma melanoneura ve E. morio (Eurytomidae) ve Cleonymus brevis ve Trigonoderus prensps (Pteromalidae) türleridir. İtalya'da A. glabripennis larvaları kullanılarak yapılan alan denemelerinde saptanmış olan sekiz ektoparazitoid türünden larvalarda en sık görülen türler olarak S. erythrocephalus ve T. princesps türlerinin saptanmış olduğu bildirilmektedir (Haack vd. 2010).

İtalya'nın kuzeyinde 2002 yılından 2012 yılına kadar yürütülen çalışmalarda turunçgil uzun antenli böceği $A$. chinensis'in en yoğun bulaşık olduğu Parabiago bölgesi civarında yumurta parasitoidi Aprostocetus anoplophorae 
Delware (Hymenoptera: Eulopidae)'nin çok iyi yerleşmiş olduğu saptanmıştır. Yürütülen biyolojik mücadele çalışmaları sonucunda A. anoplophorae'nin A. chinensis'in yumurtalarını \% 72 oranında parazitlediği ve bu sonucun ümitvar bir sonuç olduğu bildirilmiştir (Herard vd. 2013).

A.B.D'de yürütülen surveyler sırasında gözle inceleme yöntemi ile zararlının konukçusu olabilecek ağaçlar incelenmiştir. Ergin çıkış deliklerine bakılmışır. Ağaç üzerinde yumurta bırakılan yerler ve beslenme yerleri incelenmiştir. Bulaşık ağaçlar kesilerek toplanıp kaldırılarak yonga haline getirilmiştir. Bulaşık ağaçların $800 \mathrm{~m}$ çevresindeki ağaçların gövdesine Imidacloprid uygulaması yapılmıştır (USDA-APHIS 2006). Bu yöntemle ABD’de 2000 ve 2005 yılları arasında, 600.000 ağaca koruyucu olarak Imidacloprid uygulaması yapılmıştır. ABD'de Chicago eyaletinde 1998-2008 y1lları arasında ortalama 1800 adet ağaç kesilmiştir. Newyork'ta 2005 sonuna kadar 6000'den fazla ağaç kesilerek imha edilmiştir. New Jersey'de ise 600 adet ağaç kesilmiştir. Kanada'da 2003'te Toronto'da zararlının potansiyel konukçusu olabilecek 25.000 adet ağaç kesilerek imha edilmiştir. Bu ağaçların yalnızca 600 adedinin Anoplophora glabripennis ile bulaşık olduğu belirlenmiştir. ABD ve Kanada'da, 21.000 ve 25.000 adet bulaşık ve diğer risk altındaki ağaçların eradikasyon masrafları 30 Eylül 2009 itibarı ile toplam 398 milyon \$ harcama yapılmıştır. Şikago'da 10 yilın sonunda eradikasyon masrafi 63 milyon \$ olmuştur (Warren vd. 2009).

Anoplophora glabripennis (Motschulsky) (Coleoptera: Cerambycidae) ile ilgili olarak ABD Massachusetts'de 20092011 yılları arasında erkek bireylerin feromonlarını içeren cezbeci tuzakların etkinliğini belirlemek için tuzakla yakalama çalışmaları yapılmıştır. Çalışma sonucunda tuzakların sürvey çalışmalarında izleme amacı ile kullanılabileceği ancak, popülasyon yoğunluğunu izlemede kullanılamayacağı belirlenmiştir. İzleme amaçlı tuzakların özel alanlarda bu istilacı türün mücadele masraflarını azaltmada, erken tespitte ve diğer bulaşık ağaçların zamanında imhasının sağlanması açısından kullanılabileceği bildirilmektedir (Nehme vd. 2013).

Çin'de yürütülen eradikasyon çalışmalarında A. glabripennis erginlerinin beslenme ve yumurta bırakma gibi aktiviteler için ağaç gövdesinde dolaşmasından yararlanarak kimyasal mücadelesinde Cypermethrin ile gövdenin kaplanması şeklinde uygulama yapılmaktadır. Larvaların bulunduğu deliklere alümiyum fosfit içeren tahta çubukların sokulması ile larvaların ölmesi sağlanmaktadır. Erginlerin toplanması mekanik bir mücadele yöntemi olarak kullanılmaktadır. Bu yolla 500.000 adet ergin toplanmıştır.

\subsection{Karantina Önlemleri}

Avrupa Birliğinin 1 Mart 2012 tarihli (2012/138/EU) Anoplophora chinensis'in girişi ve yayılışını engellemek için alınması gereken acil durum önlemleri aşağıda bildirilmiştir.

1. Bulaşık olduğu bilinen ülkelerden Acer spp. bitkilerinin ithalinin yasaklanması.

2. Ülke içerisinde sürveylerin tüm yıl boyu yürütülmesi.

3. Zararlının tespit edildiği yerlerde eradikasyonu için bitkilerin imha edilmesi ve yayılışının engellenmesi için takip edilmesi ve sınırlandırma yapılması ve bulaşık olduğu belirlenen alan dışına bitki çıkışının yapılmaması.

4. Zararlının konukçusu olmayan bitki türlerinin dikilmesinin tercih edilmesi.

5. Zararlının bulaştığının tespit edildiği alanlardan diğer bölgelere Akçaağaç nakledilmesinin yasaklanması.

6. Sürveyler sırasında zararlının saptandığı alanlarda haritalama yapılarak sınırlandırma alanlarının belirlenmesi.

7. Bulaşık olduğu bilinen ülkelerden getirilen bitkilerin dağıtım yerlerinin belirlenmesi.

8. Böceğin zararı konusunda toplumda bilinçlendirme yapılması.

9. Zararlının konukçusu olan bitkilerin ithalatında özel şartların gündeme getirilmesi.

Önlem olarak, ithal edilen bu tür fidanların dağıtım yerlerine gönderilmeden önce en az 2 y1l bekleme alanlarında takibe alınması ve yılda en az 6 kez zararlının varlığının kontrol edilmesi ve bulaşık bulunan bitkilerin kesilip yakılarak eradikasyonunun sağlanması gerekmektedir (EPPO 2015).

\section{Sonuç ve Öneriler}

Söz konusu zararlı organizmanın yayılışını önlemek ve tespit edildiği yerlerde alınacak önlemleri belirlemek amacıyla hazırlanan zararlı risk analizi sonucunda turunçgil uzun antenli böceği Anoplophora chinensis'in ülkemiz için risk oluşturduğu ortaya konmuştur. Turunçgillerin yetiştirildiği Ege, Akdeniz ve Marmara Bölgelerine bulaşma olduğu takdirde ciddi tehdit oluşturabilmesi mümkün görülmektedir. Karantina organizması olan zararlının turunçgil üretim alanlarına yayılması durumunda önemli ekonomik kayıplara neden olabileceği düşünülmektedir. Ülkemizde Karadeniz Bölgesinde yetiştirilen findık bitkisi de bu zararlının konukçuları arasında bulunduğundan findık alanlarının da bu zararlının tehdidi altında olması söz konusudur.

Dünyada turunçgil uzun antenli böceğinin mevcut bulunduğu ülkelerde mücadele ve eradikasyon çalışmaları için yapılan harcamaların oldukça önemli miktarları bulduğu bugüne kadar yürütülmüş olan çalışmalardan anlaşılmaktadır. Zararlı türün eradikasyonu için uzun soluklu bir mücadele yapılması gerekliliği dikkate alınacak olursa ülkemizde zararlının yayılmasının önüne geçilmesi daha da önem kazanmaktadır. Bulaşık bitkilerin imhası ve kimyasal mücadelesi için yapılacak işlemlerin ekonomik olarak oldukça maliyetli olacağı görülmektedir. Ayrıca, zararlı ile mücadelede önemli miktarlarda insektisit kullanımı gerekeceğinden bunun da çevreye ve doğal faunaya olumsuz yan etkilerinin görülmesi muhtemel bir durum olarak karşımıza çıkmaktadır. 
Ülkemize çeşitli Avrupa ülkeleri ve özellikle zararlının mevcut bulunduğu İtalya'dan her yıl çok sayıda bitki ve bitkisel üretim materyali ithal edilmektedir. İthal edilen bitkiler ile giriş yapan bu zararlının yeni alanlara yayılması durumunda kontrol altına alınması oldukça zor olacağından ülkemiz için ciddi tehdit oluşturabileceği düşünülmektedir. Bu nedenle bulaşık olduğu bilinen ülkelerden bitki ithaline kısıtlama getirilerek, ülkemizde mevcut yerel bitki türlerinin kullanımı özendirilmelidir.

Ülke içerisinde zararlının keşif sürveylerinin yürütülmesi, tespit edildiği yerlerde eradikasyonu ve yayılmasının önlenmesi için gerekli tedbirlerin ihmal edilmeden yürütülmesi gerekmektedir. Belediyeler ve Bakanlıklar tarafından afiş ve posterler hazırlanmak suretiyle zararlının tanıtımı yapılarak, görüldüğünde ilgili kuruluşlara haber verilmesi yönünde toplumda bilinçlendirme çalışmaları yapılmalıdır.

\section{Kaynaklar}

Adachi I., (1990), Control Methods for Anoplophora malasiaca (Thomson) (Coleoptera: Cerambycidae) in Citrus Groves, II. Application of Wire Netting for Preventing Oviposition in a Mature Grove, Applied Entomology and Zoology, 25(1), 79-83.

Altunışık S., (2015), Anoplophora chinensis, Turunçgil tekeböceği, İstanbul Büyükşehir Belediyesi, Park Bahçe Yeşil Alanlar Daire Başkanlığı, http://www.avrupaparkbahceler.com/makale.php?baslik=turuncgil-teke-bocegi\&no=57, [Erişim 17 Ocak 2018].

Baker R., Eyre D., (2006), Pest Risk Analysis for Anoplophora chinensis, CSL, York, UK.

CABI, (2010), Anoplophora chinensis (black and white citrus longhorn), Crop Protection Compendium, Wallingford, UK.

CABI, (2015), Anoplophora chinensis [Distribution map], http://www.cabi.org/isc/abstract/20083279223, [Erişim 24 Ocak 2018].

EFSA, (2010), EFSA Panel on Plant Health (PLH); Scientific Opinion on a technical file submitted by the Japanese Authorities to support a derogation request from the EU import requirements for bonsai and topiary trees that are host plants of Anoplophora chinensis, EFSA Journal 2010;8(10):1849.

EPPO, (2015), Anoplophora chinensis, https://gd.eppo.int/taxon/ANOLCN/distribution, [Erişim 24 Ocak 2018].

Haack R.A., Hérard F., Sun J., Turgeon J.J., (2010), Managing invasive populations of asian longhorned beetle and citrus longhorned beetle: A Worldwide Perspective, Annual Review of Entomology, 55, 521-546.

Herard F., Krehan H., Benker U., Boegel C., Schrage R., Chauvat E., Ciampitti M., Maspero M., Bialooki P., (2005), Anoplophora in Europe: infestations and management responses, In: Proc. 16th U.S. Dept. Agric. interagency research forum on gypsy moth and other invasive species 2005. USDA, For. Serv. Gen. Tech. Rept. NE-337: 35-40.

Herard F., Roques A., (2009), Current status of Anoplophora spp. in Europe and an update on suppression efforts, 2009 USDA Research forum on invasive species, https://www.nrs.fs.fed.us/pubs/gtr/gtr-nrs-p-51papers/19herard-p-51.pdf, [Erişim 8 Temmuz 2015].

Hérard F., Maspero M., Ramualde, N., (2013), Potential candidates for biological control of the Asian longhorned beetle (Anoplophora glabripennis) and the citrus longhorned beetle (Anoplophora chinensis) in Italy, Journal of Entomological and Acarological Research, 45(s1), 22.

Hızal E., Arslangündoğdu Z., Göç A., Ak M., (2015). Türkiye istilacı yabancı böcek faunası yeni bir kayıt Anoplophora chinensis (Forster, 1771) (Coleoptera: Cerambycidae), İstanbul Üniversitesi Orman Fakültesi Dergisi, 65(1), 7-10.

Maspero M., Cavalieri G., D’Angelo G., Jucker C., Valentini M., Colombo M., Herard F., Lopez J., Ramualde N., Ciampitti M., Caremi G., Cavagna B., (2007), Anoplophora chinensis - eradication program in Lombardia (Italy), https://www.eppo.int/ACTIVITIES/ plant_quarantine/shortnotes_qps/anoplophora_chinensis_eradication, [Erişim 8 Temmuz 2015].

Nehme M.E., Keena M.A., Meng P., Trotter R.T, De Moraes C., Mescher M., McFarland C., Sawyer A., Hoover K., (2013). Development of a trapping system for Asian longhorned beetle using semiochemicals, Journal of Entomological and Acarological Research, 45(s1), 20.

Roselli M., Bianchi A., Nuccitelli L., Sabbatini G.P., Roversi P.F., (2013), Control strategies of Anoplophora chinensis in an area of considerable artistic and archaeological value in Rome, Journal of Entomological and Acarological Research, 45(1), 27-29.

Smith I.M., McNamara D.G., Scott P.R., Holderness M., (1997), Quarantine Pests for Europe, 2nd Edition, CABI / EPPO, Wallingford, $1425 \mathrm{ss}$.

USDA-APHIS, (2006), The Asian longhorned beetle cooperative eradication program, ALB Newsletter, 1, USDA Animal and Plant Health Inspection Service, http://www.aphis.usda.gov/plant_health/plant_pest_info/asian_lhb/alb_pdfs/newsletters/ alb_newsletter_9_06.pdf, [Erişim 22 Haziran 2015].

Van der Gaag D.J., Ciampitti M., Cavagna, B., Maspero M., Herard F., (2008), Pest Risk Analysis: Anoplophora chinensis, Plant Protection Service, Netherlands, http://edepot.wur.n1/117610, [Erişim 8 Temmuz 2015].

Van der Gaag D.J., Sinatra G., Roversi P.F., Loomans A., Herard F., Vukadin A., (2010), Evaluation of eradication measures against Anoplophora chinensis in early stage infestations in Europe, Bulletin OEPP/EPPO Bulletin 40, 176-187.

Warren J., Cline S., Lemay A., Hiser A., Lewis R., Boehm A., Fite R., Twardowski J., (2009), USDA-APHIS Asian longhorned beetle eradication programme - Decision support for the APHIS management team, A report prepared for the USDA-APHIS-PPQ Executive team, USDA-APHIS, 87ss. 